Article

\title{
Factors Influencing the Quality of Life of Empty Nesters: Empirical Evidence from Southwest China
}

\author{
Chenghua Wang ${ }^{1}\left(\mathbb{D}\right.$, Banghui Zhang ${ }^{1}$, Judit Oláh ${ }^{2,3, * \mathbb{D}}$ and Morshadul Hasan ${ }^{4}(\mathbb{D}$ \\ 1 School of Public Affairs, Chongqing University, Chongqing 400044, China; wangwan198199@163.com (C.W.); \\ zbhmx@cqu.edu.cn (B.Z.) \\ 2 Faculty of Economics and Business, University of Debrecen, 4032 Debrecen, Hungary \\ 3 TRADE Research Entity, North-West University, Potchefstroom 2351, South Africa \\ 4 Károly Ihrig Doctoral School of Management and Business, University of Debrecen, 4032 Debrecen, Hungary; \\ mohammad.hasan@econ.unideb.hu or arif.morshad@gmail.com \\ * Correspondence: olah.judit@econ.unideb.hu
}

Citation: Wang, C.; Zhang, B.; Oláh, J.; Hasan, M. Factors Influencing the Quality of Life of Empty Nesters: Empirical Evidence from Southwest China. Sustainability 2021, 13, 2662. https://doi.org/10.3390/su13052662

Academic Editor: Andrea Appolloni

Received: 20 January 2021

Accepted: 12 February 2021

Published: 2 March 2021

Publisher's Note: MDPI stays neutral with regard to jurisdictional claims in published maps and institutional affiliations.

Copyright: (๑) 2021 by the authors. Licensee MDPI, Basel, Switzerland. This article is an open access article distributed under the terms and conditions of the Creative Commons Attribution (CC BY) license (https:// creativecommons.org/licenses/by/ $4.0 /)$.

\begin{abstract}
Quality of life is a widely accepted concept based on the notion that people's lives have been subject to rapid development and industrialization. This study aims to explore the impact of different factors on the quality of life of empty nesters in Southwest China. The main factors explored are resilience and social supports (SS), highlighted here from different perspectives. Moreover, the correlations between other variables and quality of life are shown here. This study experimented with a hierarchical multiple regression model from survey data with 3583 valid responses. It argued that both resilience and social supports, including family members and friends, are significantly correlated with the Chinese empty nesters' quality of life. Family support and friend support play a significant mediating role in the association between resilience and quality of life. However, neither government nor nongovernmental support significantly influences the quality of life. Therefore, the hypothetical recommendations of this study have been partially confirmed. The findings of this study provide a more comprehensive understanding of the overall mental and physical health of Chinese empty nesters.
\end{abstract}

Keywords: quality of life; empty-nesters; resilience; social support; multiple mediation model

\section{Introduction}

The age structure of the population is changing worldwide every day. People live longer, so the share of older people in the total population is overgrowing [1-3]. Khan (2019) mentioned that by 2030, one-fourth of the Asian people would be over 60 years old. Taking this into consideration, China also accounts for one-third of the total population of Asia. Noticeably the number of older people in China is increasing fast $[4,5]$. The so-called "empty nest" refers to a family in which children are separated from their parents' families after they grow up, leaving only the older generation to live alone. Once the spouse dies, the family life cycle enters the widowed period.

The empty nest period and the widowhood period are two critical stages in life in which the elderly are prone to difficulties [6-8]. Wu et al. [9] stated that "the children have left home like birds flying away from the nest, and the elderly are left behind lonely and without the care of their children." Lv et al. [8] also used the same concept, noting that empty nesters may not have any children, and even if they do, they are always far away from their parents. There are several reasons behind the development of the empty nesters' family, for example, rapid urbanization, accelerated economic growth, the imbalance between rural and urban development, and others. Children's departure from their home has visible impacts, including parents suffering from high levels of depression and loneliness [6]. He et al. [10] mentioned that empty nesters are older people over 60 years old who live with other relatives at home, are single, or live with their spouses or other elders. Regardless, with 
the increase in the ageing population, the status of empty nesters has gradually attracted people's attention - the empty-nest elderly need to be taken care of to improve the quality of life. The empty nesters' quality of life is different from those living with their children, even with the other family members and well-wishers. It seems very clear that empty nesters usually have a low quality of life compared to those who are not empty-nesters. Several forces have a significant impact that influences the quality of life of empty nesters from different perspectives. This multidimensional perspective includes both subjective and objective aspects such as financial soundness, mental health, social status, physical health, dependence, etc. However, in the last few decades, quality of life and its related influencing factors among the elderly have drawn much attention from researchers for the benefit of improving older people's wellbeing [11-15]. Prior studies have indicated that both resilience and SS are closely connected to quality of life $[16,17]$. However, less attention was given to the meaning and implications of these three variables, such as the mediating roles on the association between resilience and quality of life. Moreover, most of the previous studies on SS examined the general or aggregate index of SS, devoting less attention to its sources, that is, the support derived from a specific relationship [18-21]. In demographic and sociological studies, it has been revealed that ageing is a universal social phenomenon around the world, including in China [22,23]. Wu et al. (2018, pp. 1) [17] mentioned that the number of older people who are more than 60 years old would increase to 358 million by 2030; this amount will make up more than $25.3 \%$ of the total population of China. In any case, the concept of "empty nester" is put forward based on the family life course theory $[24,25]$. It refers to older people who are living alone or living independently with their spouses.

It should be noted that the empty nest stage occurs when offspring grow up and leave home, regardless of whether they live with their spouses or not [26]. Some other studies referred to them as "baby boomers" $[27,28]$. However, empty nesters will face various challenges and experiences due to the variations in their activities. These are mostly holding onto existing activities, expressing reluctance to engage in new activities, being unable to deal with necessary long-distance activities, losing their relatives and friends, and so forth [7]. Without support from societal forces such as family, relatives, or even friends, the empty nesters suffer different risky circumstances such as being unhappy, losing sleep, and failing to overcome difficulties [29]. These negative experiences can lead to depression, increased stress, anxiety, and other adverse symptoms, resulting in a reduced quality of life [30].

In most cases, some of the literature has frequently studied common variables within a narrower concept and with a smaller sample size. Moreover, one important variable related to SS is nongovernmental support, which is missing in the current literature. Therefore, this is considered a gap in this research field. Hence the question arises as to whether nongovernmental support adds some extra significance to the resilience and quality of life. In most cases, researchers have skipped nongovernmental support toward the quality of life. In other instances, only the governmental contribution fails to meet the demands for a better quality of life. Therefore, this study extends the research into nongovernmental support as an essential element of SS. The nongovernmental organizations have significant contribution toward community through different social responsibility activities [31]. However, the mediating effect is extended here to both governmental and nongovernmental supports to show more accurate influences. This study trialed a wider research area and comparatively larger sample size. The present study uses a large sample $(\mathrm{N}=$ 3583) collected from the empty nesters in southwest China. The study aimed to verify the correlations among SS, resilience, and the quality of empty nesters' life. A test of mediating roles of different sources of support from society (i.e., family support, friends' support, nongovernmental and governmental support) in the correlation between resilience and the quality of life is also examined here. 


\section{Literature Review and Hypothetical Design}

The literature on quality of life has been widely studied from different perspectives; however, the literature showing the impact of resilience and SS is not highly developed regarding Southwest China. However, the hypotheses of this study are based on the following review concepts. First of all, resilience is a key component of successful ageing, and the positive correlation between resilience and quality of life has been verified in many studies [21,32-38]. Different factors influence the quality of life, such as income, savings, other economic conditions, additional supports, administrative operations, good governance, sound physical conditions, and so forth [19,39-41]. A recent study conducted by Wang and $\mathrm{Xu}$ [42] suggests a significant positive relationship between resilience and quality of life among older people (with a mean age of 54.57 years old) who had lost their only child in the 2008 Wenchuan earthquake. Resilience also helps the elderly survive with stressors to improve their cognitive, psychosocial functioning, and physical function [43-45]. These are consistent with the multidimensional concept of quality of life in mental, physical, social, and economic circumstances [46,47]. Another study was done by [48], which specified a different distance-based resilience strategy that may also influence different services related to the quality of life. Distance-based resilience strategy is highly appropriate, especially in any crisis or pandemic moment such as the COVID-19 crisis; that is an appropriate example of this distance-based resilience strategy. Based on these concepts, hypotheses 1 is drawn here.

Hypothesis 1. Resilience has a significant impact on the quality of life of empty nesters in Southwest China.

Another influential force is SS that is also related to improving the quality of life of empty nesters. SS strongly supports the alleviation of the negative aspects of the quality of life of elderly empty nesters. Some other studies suggest that SS is positively associated with quality of life [49-53]; even people with high SS reported better physical and psychological health [17]. Moreover, based on the sample of emerging adults attending college, Lee \& Dik [54] examined how sources of SS intersect with stress and health. This study also mentioned that supports from family was a kind of stress buffer, which has an adverse connection between stress and depressive symptoms. Another study on mothers of children by Y. Wang et al. [55] shows that support from friends and family has a mediating role in the relationship between parenting stress and life satisfaction. However, they did not investigate the other supports. However, very little research focused on the connection between different SS sources and older people's quality of life. This paper would be a pilot study to explore the effect of different sources of SS on the quality of life of empty nesters in China. Based on these concept Hypotheses 2, 2a, 2b, 2c, and 2d are drawn here.

Hypothesis 2. SS significantly influence the quality of life of empty nesters in Southwest China.

Hypothesis 2a. Family support has a significant impact on quality of life of the empty nesters in Southwest China.

Hypothesis $\mathbf{2 b}$. Friends' support has a significant impact on quality of life of the empty nesters in Southwest China.

Hypothesis 2c. Nongovernmental support has a significant impact on quality of life of the empty nesters in Southwest China.

Hypothesis 2d. Governmental support has a significant impact on quality of life of the empty nesters in Southwest China.

As a mediating variable, SS is regarded as a surviving resource that is commonly associated with encouraging adaptation and wellbeing in different classes of people, and 
even disaster survivors are an excellent example of this study [56]. Moreover, support from society was certainly related to the quality of life among the Chinese rural elderly (aged 60 and above) [17]. Besides, it had an indirect influence on the quality of life through resilience $[17,21,42]$. Resilience also somewhat mediates the connection between the quality of life and SS among the rural Chinese elders. It indicates that a higher level of SS leads to a comparatively stronger resilience, leading to a better quality of life [17]. In this case, support from different subjects and support availability can also act as strong enablers for resilience and quality of life [42]. It can be seen that many studies have highlighted the mediation role of supports from society between resilience and quality of life. However, very few research types examine the mediation effect of governmental and nongovernmental support between resilience and quality of life. Based on these concepts, this study estimates another hypothetical relationship with the control variables.

Hypothesis 3. Demographic characteristics have a significant influence on the quality of life of empty nesters in Southwest China.

The hypothetical design of this study is mentioned in the following section in Figure 1, which includes all hypothetical relationships in one diagram.

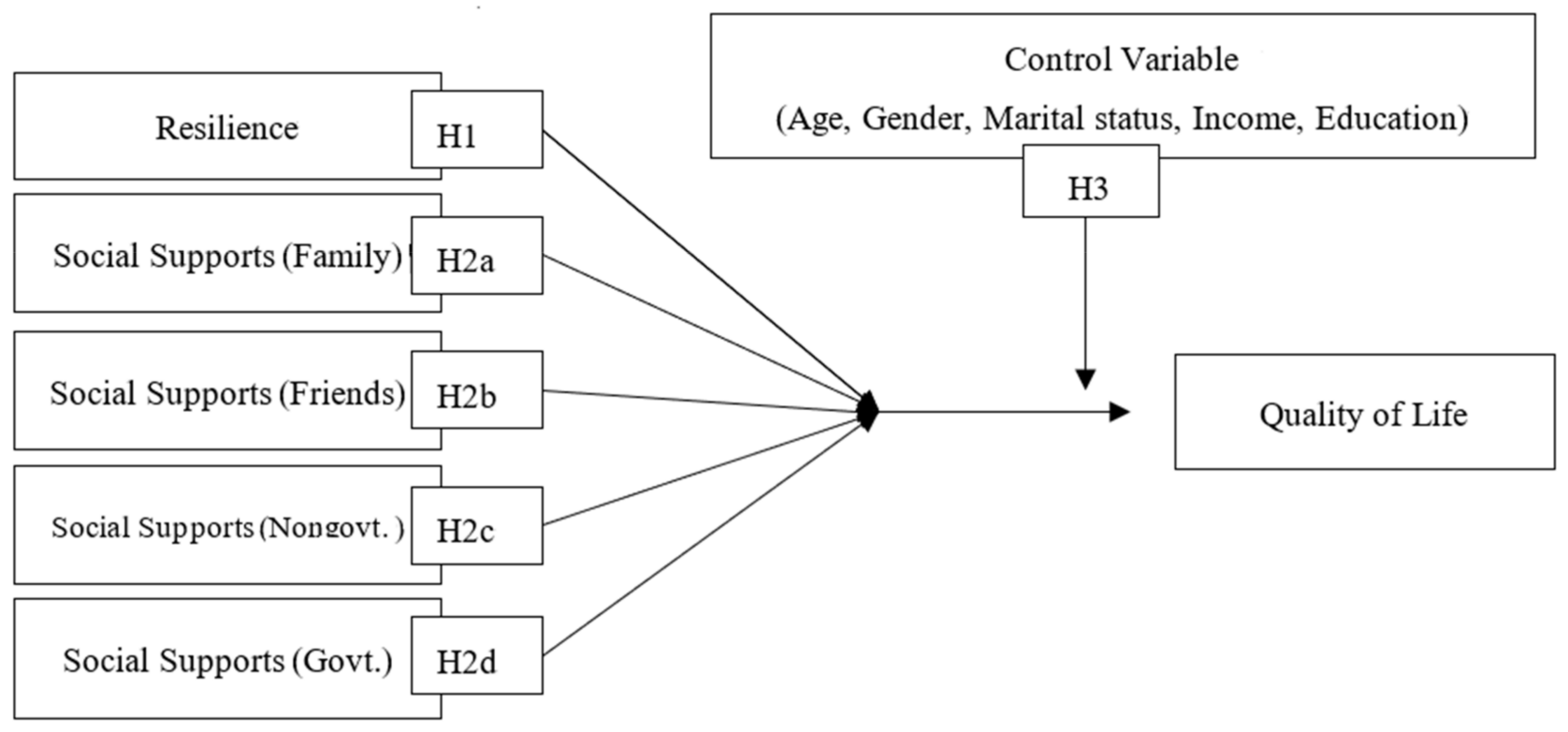

Figure 1. Hypothetical design. Source: author's illustration.

Based on the above literature, this study has found a gap in this research field as well as has specified the objectives of this study to find the impact of resilience and SS (including nongovernmental supports) on the quality of life in the empty nesters in Southwest China.

\section{Analysis Methods and Materials}

\subsection{Variable Measures Quality of Life}

3.1.1. Dependent Variable (Quality of Life)

Quality of life is a widely accepted theory that believes that people's lives have been rapidly developed and industrialized. This term was coined in the United States after the Second World War. The meaning of a good life was limited to simply owning or not owning typical commodities. However, the concept has gradually developed, and its scope expanded to cover life satisfaction, satisfying personal needs, and desires, and modifying the personal environment to better respond to life circumstances [57-60], including the reactions to life circumstances, which can be varied dramatically with age [61]. The WHO 
quality of life questionnaire evaluates the elderly's quality of life in the present study. It comprises four areas that include twenty-four self-report elements, such as environmental health, social relationships, physical and psychological health. A 5-point Likert scale was used (5 means entirely and $1=$ not at all), and a higher score indicates a higher level of quality of life.

\subsubsection{Independent Variables (Resilience and Social Supports)}

Based on the concept of quality of life, other measures have been considered from the relevant literature. For example, this study mainly follows the evaluation system of resilience from Laura Campbell-Sills \& Stein [62]. They also used a 5-point Likert scale ( 5 means entirely and $1=$ not at all); the total score of resilience ranges between 0 and 40 , where a high score indicates better resilience. This scale has also been validated from different studies based on different countries, and therefore, the scale used in this study is valid and reliable $[63,64]$. Another crucial variable concept of this study is SS. The literature mainly focuses on the support of family, friends, relatives, and other people (i.e., support from teachers, classmates, or relatives). Government support as an influencing factor for measuring resilience and quality of life, particularly in the material conditions of living, including income inequality and poverty eradication $[65,66]$, overall life satisfaction due to decent living environment [67], and social safety [68]. This scale is reliable and valid in many languages and different countries [69]. Moreover, nongovernmental organizations (NGOs) play a strategic role in the wellbeing of civil society. In some cases, they also take supports from the governments. NGOs support the solution of various vital issues of social wellbeing by strengthening individual and organizational capabilities, providing information and knowledge resources, adjusting material quality resources, establishing mutual support alliances and bridges for cross-sectoral differences, and so forth [70-74]. Based on those concepts, this variable has been selected by following some of the literature. A 7-point Likert scale (7 defines strongly agree and 1 defines strongly disagree) is used here, resulting in a total score ranging from 12 to 84 . The higher the score, the higher the level of SS that the individual perceived.

\subsubsection{Control Variables}

Control variables are also very significant in social science research; therefore, this study also applied the control variables concept to show the real impact of these variables in real implication. Since this study is based on primary data, respondents' age, income level, marital status, education level, and gender are considered as control variables. However, the impact of these control variables is not emphasized as having a higher potential value, and this study mainly focused on the relationship between the dependent and independent variables.

\subsection{Model Design}

The analysis strategy is divided into three stages. First, Pearson's correlation matrix for the dependent variable as well as covariates was obtained to test the correlations. In the second stage, a series of hierarchical multiple regressions were conducted multiple times. In this stage, six steps were followed; first, a regression that contained only the covariance variables (such as gender, age, marital status, education, and income) was entered in block 1. Then, resilience was fitted in block 2 , followed by the social support variables such as family support in block 3 , friend support in block 4, nongovernmental organizational support in block 5, and finally, governmental support in block 6 . The gradual changes of the $\mathrm{R}^{2}$ and F-values were used to assess the maximum effects of stated variables in each model. Based on these concepts, the models are formulated in the forms given below:

- Block-1: $Y=\beta_{0}+\beta_{1} *$ age $+\beta_{2}^{*}$ gender $+\beta_{3}^{*}$ maritalstatus $+\beta_{4} *$ education $+\beta_{5}$ * income $+\varepsilon i$;

- Block-2: $Y=\beta_{0}+\beta_{1} *$ age $+\beta_{2} *$ gender $+\beta_{3} *$ maritalstatus $+\beta_{4} *$ education $+\beta_{5} *$ income + $\beta_{6}{ }^{*}$ resilience $+\varepsilon i$; 
- Block-3: $Y=\beta_{0}+\beta_{1} *$ age $+\beta_{2} *$ gender $+\beta_{3} *$ maritalstatus $+\beta_{4} *$ education $+\beta_{5} *$ income + $\beta_{6}{ }^{*}$ resilience $+\beta_{7}{ }^{*}$ family_support $+\varepsilon i$;

- Block-4: $Y=\beta_{0}+\beta_{1} *$ age $+\beta_{2} *$ gender $+\beta_{3} *$ maritalstatus $+\beta_{4} *$ education $+\beta_{5} *$ income + $\beta_{6}{ }^{*}$ resilience $+\beta_{7}{ }^{*}$ family_support $+\beta_{8}{ }^{*}$ friend_support $+\varepsilon i$;

- Block-5: $Y=\beta_{0}+\beta_{1} *$ age $+\beta_{2} *$ gender $+\beta_{3} *$ maritalstatus $+\beta_{4} *$ education $+\beta_{5} *$ income + $\beta_{6}{ }^{*}$ resilience $+\beta_{7}{ }^{*}$ family_support $+\beta_{8}{ }^{*}$ friend_support $+\beta_{9}{ }^{*}$ nongovt_support $+\varepsilon i$;

- Block-6: $Y=\beta_{0}+\beta_{1} *$ age $+\beta_{2} *$ gender $+\beta_{3} *$ maritalstatus $+\beta_{4} *$ education $+\beta_{5}{ }^{*}$ income + $\beta_{6}{ }^{*}$ resilience $+\beta_{7}{ }^{*}$ family_support $+\beta_{8}{ }^{*}$ friend_support $+\beta_{9}{ }^{*}$ nongovt_support $+\beta_{10}$ * govt_support $+\varepsilon i$.

In the third stage, an analysis with quality of life as the response variable, resilience as the covariate, and the source of SS as the mediating variables was performed to find out the mediation outcome of the sources of SS on the connection between resilience and quality of life.

\subsection{Participants and Procedure}

The Southwest region of China was selected as the area of this study, not including Tibet, an autonomous region. It may have some dissimilarities in the relevant categories and various other data. According to the research area selection concept, the other four provinces (Yunnan, Guizhou, Chongqing, and Sichuan) are prespecified as the study area. Following this, three cities in each province have been selected. Specifically, the city selection process designates the city with the largest number of rural inhabitants as the study area. According to this criterion, the top three cities of the specified province were selected. For example, Xuanwei, Qujing, and Dali were selected from Yunnan; Zunyi, Liupanshui, and Anshun were selected from Guizhou; Wanzhou, Hechuan, and Jiangjinwere selected from Chongqing; and Mianyang, Nanchong, and Luzhou were selected from Sichuan. The capital city belongs to the largest rural area among all the selected provinces; therefore, Kunming, Chongqing, Chengdu, and Guiyang were not selected as they have more than five times the rural area of the other cities. Thereby, the result of this survey may produce data bias.

After selecting the main study area, a direct survey was conducted in 12 cities; however, selecting the specific area in the city was made according to surveyors' preference and opportunities; more particularly, the survey teams collected the responses based on their communication availability. The target population was 5000 respondents; therefore, a structured questionnaire was prepared. The participants are specified that they had to be over 60 years old and living in rural areas. However, 3823 responses were collected, and 3583 responses are finally selected for the study after screening the data. The screening process was carried out systematically; first, the researchers checked the responses for preliminary screening. The incomplete response was not calculated at this stage, and the responses also seemed to be very inconsistent, so no further processing was required. From the collected data, almost $60 \%$ of respondents are male, and $40 \%$ of respondents are female, in numbers 2150 males and 1433 females. The sample collection was also followed by a multiple-stage sampling method. Although our minimum age limitation was 60, in some cases, the survey team found some people who were very close to meeting the research interviewees' criteria whose age was also very near to 60 . Most of them were male; in some cases, the woman was unwilling to participate in the survey due to some unknown reasons. Although it was the same for both males and females, the female is typically unlikely to participate in the survey than the men. In some cases, secondary data was necessary, and this was followed in a structured way, as in other studies [75-77].

\subsection{Reliability Testing}

The reliability test results are shown here to show the reliability of the data. The result is "good" in most cases except for the resilience, which has an "excellent" Cronbach's alpha value. The details of Cronbach's alpha values are given in the following Table 1. 
Table 1. Reliability statistics.

\begin{tabular}{ccc}
\hline Variables & Cronbach's $\alpha$ Value & Interpretation \\
\hline Quality of Life & 0.856 & Good \\
Resilience & 0.901 & Excellent \\
Family & 0.856 & Good \\
Friends & 0.890 & Good \\
Nongovernment & 0.835 & Good \\
Government & 0.874 & Good \\
\hline
\end{tabular}

Source: Authors' compilation.

\subsection{Study Framework}

This study followed a structured design process detailed in Figure 2 below, which shows the procedures starting from the article searching and finishing at the start of the paper writing.

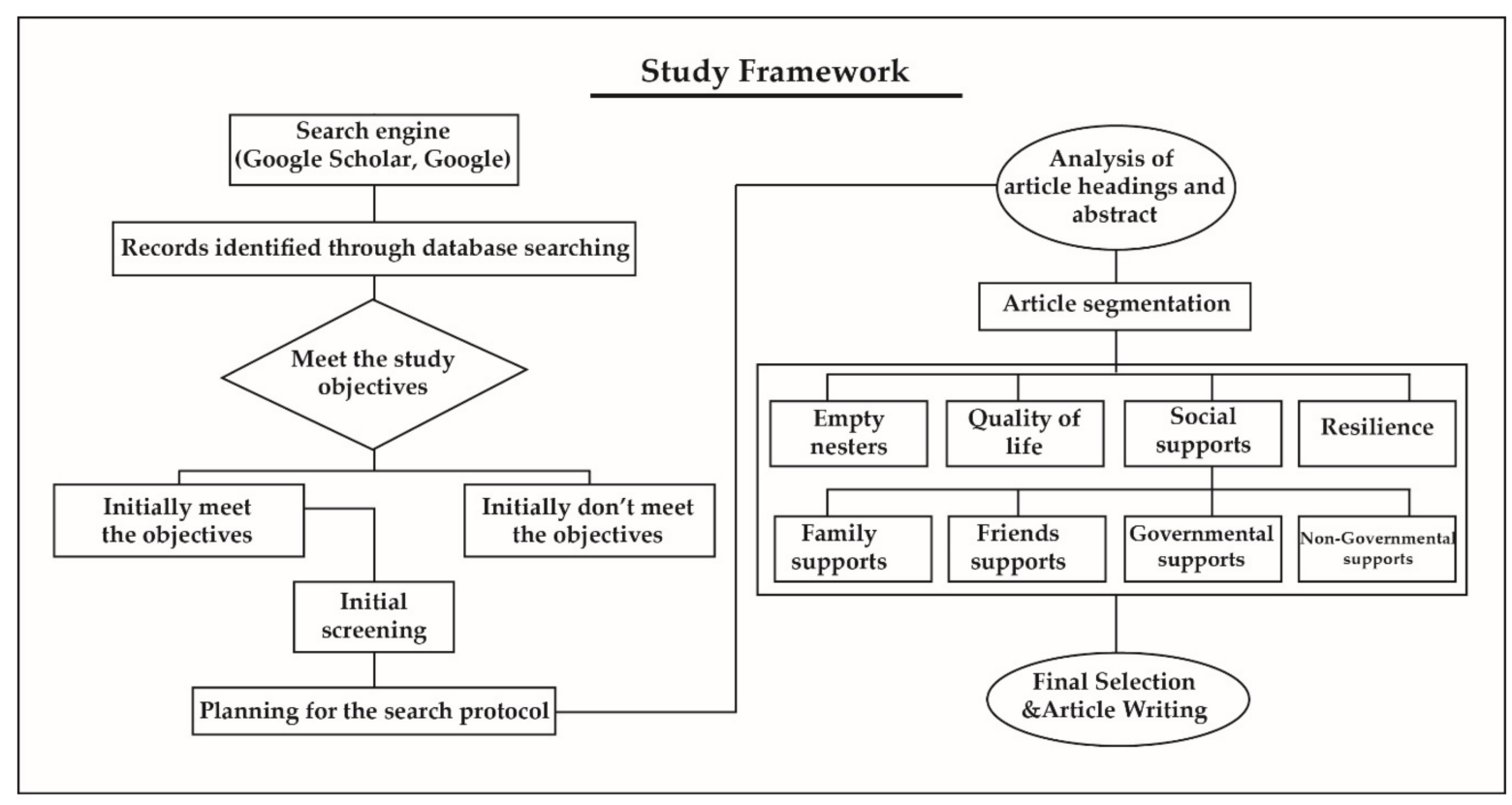

Figure 2. Research framework. Source: authors illustration [75,78-83].

\section{Results and Analysis}

This study has highlighted significant relations between the variables that help explore the comparability between them. Research on these individual concepts has already been carried out in different literature fields; however, this study explores the combined relationship between these factors. Pearson's correlation matrix of all the variables is presented in Table 2 to show the correlation between the stated variables. As expected, the level of resilience is positively correlated with quality of life, as well as the four SS sources (i.e., family, friends, governmental, and nongovernmental supports) at the level of 0.001 . Table 2 also reveals that four sources of supports positively related to the quality of life at the level of 0.001. Meanwhile, the correlation coefficients among the three sources of support are all greater than 0.5 , and very relevant relationships are obtained between the four sources at the 0.001 level. Moreover, compared with the standard reference score of quality of life, empty-nesters feel the lower quality of life given that the average score is 11.42. 
Table 2. Correlations and descriptive statistics of the variables.

\begin{tabular}{|c|c|c|c|c|c|c|c|c|}
\hline List of Variables & 1 & 2 & 3 & 4 & 5 & 6 & Mean & SD \\
\hline 1. Quality of life & 1 & & & & & & 11.42 & 3.08 \\
\hline 2. Resilience & 0.201 & 1 & & & & & 17.89 & 2.88 \\
\hline 3. Family support & 0.232 & 0.301 & 1 & & & & 16.67 & 4.88 \\
\hline 4. Friends' support & 0.184 & 0.356 & 0.457 & 1 & & & 15.46 & 4.66 \\
\hline 5. Non-govt. support & 0.118 & 0.101 & 0.156 & 0.398 & 1 & & 12.56 & 5.01 \\
\hline 6. Government support & 0.169 & 0.450 & 0.488 & 0.521 & 0.106 & 1 & 13.86 & 4.11 \\
\hline
\end{tabular}

Source: authors' findings. Note: $\mathrm{N}=3583$. All of the correlation coefficients are significant at $p<0.001$.

In addition to Pearson's correlation matrix, a hierarchical multiple regression analysis is shown in Table 3, demonstrating the projected coefficient and significance of individual variables and the gradual changes in $\mathrm{R}^{2}$ values and F-values for the respective models. As stated earlier in the methodology section, this study experimented with five different blocks to choose the appropriate model, which is also presented here with the gradual changes in $\mathrm{R}^{2}$ and F-values. It can be seen that the $\mathrm{R}^{2}$ value of block 1 to block 6 are $0.103,0.185,0.198,0.209,0.231$, and 0.258 , respectively. Here the demographic variables are also considered to be covariates. First of all, all the demographic variables are ultimately insignificant in block 6 . The gender here is negatively significant at the 0.001 significance level. Simultaneously, both age and marital status are insignificant in the final model, while the other two important demographic variables, namely, income and education, positively influence the quality of life. Here education is comparatively less significant than income. Education is significant at the level of 0.05 , and income is significant at 0.001 level; therefore, the old ages people who have a comparatively higher level of education and a higher income always lead a better life. As indicated in Table 3, regardless of the different sources of support, the predictable coefficients of resilience on quality of life are significant at 0.001 level. Resilience has a positive impact on from block 2 to block 6 . As per block 6 , the coefficient value of resilience is 0.201 , which is the highest influencing factor compared to the other covariates. As per the literature review, this study has prespecified resilience. It has a significant impact on the quality of life; therefore, the first hypothesis is supported, i.e., that resilience is positively related to the quality of life among Southwest Chinese empty nesters.

Table 3. Test of predictive effects of measured variables.

\begin{tabular}{|c|c|c|c|c|c|c|}
\hline Variable & Block 1 & Block 2 & Block 3 & Block 4 & Block 5 & Block 6 \\
\hline Gender & $-0.219^{* *}$ & $-0.243^{* * *}$ & $-0.254^{* * *}$ & $-0.260 * * *$ & $-0.262 * * *$ & $-0.239^{* * *}$ \\
\hline Age & 0.062 & 0.078 & 0.084 & 0.085 & 0.083 & 0.082 \\
\hline Marital status & $0.019^{* *}$ & $0.023 *$ & 0.024 * & $0.023 *$ & 0.022 & 0.021 \\
\hline Education & $0.085 *$ & $0.086^{*}$ & $0.086^{*}$ & $0.084 *$ & $0.083 *$ & $0.082 *$ \\
\hline Income & $0.152^{* * *}$ & $0.168^{* *}$ & $0.172^{* * *}$ & $0.178^{* * *}$ & $0.181^{* * *}$ & $0.188^{* * *}$ \\
\hline Resilience & & $0.253^{* * *}$ & $0.211^{* * *}$ & $0.173^{* * *}$ & $0.180^{* * *}$ & $0.201^{* * *}$ \\
\hline Family support & & & $0.098^{* *}$ & $0.079 * *$ & $0.123^{* *}$ & $0.105^{* *}$ \\
\hline Friends' support & & & & $0.135^{* *}$ & $0.152^{* *}$ & $0.155^{* *}$ \\
\hline NGOs Support & & & & & 0.066 & 0.059 \\
\hline $\begin{array}{l}\text { Government } \\
\text { support }\end{array}$ & & & & & & 0.078 \\
\hline$R^{2}$ & 0.103 & 0.185 & 0.198 & 0.209 & 0.231 & 0.258 \\
\hline$\Delta \mathrm{R}^{2}$ & 0.103 & 0.082 & 0.013 & 0.011 & 0.022 & 0.027 \\
\hline$\Delta \mathrm{F}$ & $9.88^{* * *}$ & $28.87^{* * *}$ & $7.58^{* * *}$ & $5.66^{* *}$ & 6.18 & 0.882 \\
\hline
\end{tabular}

Source: authors' findings. Note: $\mathrm{N}=3583$. $^{* * *} p<0.001 ;{ }^{* *} p<0.01{ }^{*} p<0.05$.

Table 3 also reveals that family support and friends' support positively impact the quality of life; although, friends' and family support are significant at the 0.01 level. However, the other two types of SS show different results, such as both government and 
nongovernmental supports show an insignificant correlation with the quality of life. The hypothesis is that the sources of support are positively related to Southwest Chinese empty nesters' quality of life and is partially supported here. Therefore, Hypotheses $2 a$ and $2 b$ are supported in this study, as they have been in some other previous studies discussed in the discussion section. However, the other two Hypotheses, $2 \mathrm{c}$ and $2 \mathrm{~d}$, are not supported in this study as both are insignificant. H3 (age, marital status) is also rejected here, although H3 (gender, education, and income level) is significant. The gradual changes in $\mathrm{R}^{2}$ values and the F-values for each regression also indicate the essential predictive effects of resilience, family support as well as friends' support on quality of life.

As indicated in the earlier discussion of Table 3, unlike both governmental and nongovernmental support, the other two social supports, namely, family support and friends' support, are positively correlated with the quality of life of Southwest Chinese. Moreover, there is a significant relationship between the predictor variable and the outcome variable, indicating that there may be a mediation effect so that the mediation effect test could be continued [10]. The mediation effects of family support and friends' support rather than government and nongovernment support on the correlation between resilience and the quality of life among Chinese empty-nesters are tested in the present study. After testing with the bootstrap estimation process, quality of life and resilience have been shown here, where the quality of life was independent, and resilience was the dependent variable. Besides, family support and friends' support were entered as prespecified mediators where the bootstrap sample was specified with a doubled sample size to see the estimated impact. The results of the bootstrap estimation method are presented in Table 4, which shows the total effect of resilience on quality of life among the empty nesters in Southwest China is 0.598. It is also significant at $p<0.001$ in total effect; however, it decreases to 0.285 , which is also significant at $p<0.001$ directly when the mediators (family, friends, NGOs, and government support) are included. After experimenting with the bootstrapping at the 95 percent confidence interval, the mediation of the family and friends' support is determined. In this case, the findings in Table 4 suggest that the indirect effects of resilience on friends' and family support in terms of quality of life are significant. Therefore, the mediating role is partially confirmed here in this circumstance. However, the other two SS variables, NGOs and government, do not support the mediating roles as the value is not significant. As per Table 4, the mediating effect resilience to family support to quality of life, resilience to friend supports to quality of life, resilience to NGOs to quality of life, and resilience to government support to quality of life are $0.212,0.128,0.048$, and 0.063 , respectively. This experiment of the goodness of fit to the data shows a satisfactory result. The goodness of fit index is $91 \%$, the adjusted goodness of fit index $94 \%$, and the comparative fit index at $95 \%$ and the RMSEA are 0.088 .

Table 4. Projected effects and bootstrap confidence interval.

\begin{tabular}{|c|c|c|c|c|c|}
\hline \multirow[t]{2}{*}{ Model Pathways } & \multirow{2}{*}{$\begin{array}{c}\text { Estimated } \\
\text { Effect }\end{array}$} & \multicolumn{2}{|c|}{$\begin{array}{c}\text { Bias-Corrected } \\
95 \% \text { CI }\end{array}$} & \multicolumn{2}{|c|}{$\begin{array}{c}\text { Percentile } \\
95 \% \text { CI }\end{array}$} \\
\hline & & Lower & Upper & Lower & Upper \\
\hline Total effects & & & & & \\
\hline $\begin{array}{l}\text { Resilience to QoL } \\
\text { Direct effects }\end{array}$ & 0.598 & 0.345 & 0.898 & 0.312 & 0.901 \\
\hline $\begin{array}{l}\text { Resilience to QoL } \\
\text { Indirect effects }\end{array}$ & 0.285 & 0.112 & 0.621 & 0.098 & 0.587 \\
\hline Res to SS to QoL & 0.301 & 0.150 & 0.667 & 0.148 & 0.612 \\
\hline Resilience to family support to QoL & 0.212 & 0.056 & 0.599 & 0.051 & 0.548 \\
\hline Resilience to friends support to QoL & 0.138 & 0.021 & 0.398 & 0.026 & 0.512 \\
\hline Resilience to NGOs to QoL & 0.048 & 0.010 & 0.268 & 0.009 & 0.259 \\
\hline Resilience to govt. to QoL & 0.063 & 0.016 & 0.397 & 0.011 & 0.368 \\
\hline
\end{tabular}




\section{Discussion}

The degree of happiness experienced by individuals varies at different stages of life. As the structure of the human body changes with age, so does the happiness of people of different ages. It is believed that a persons' happiness decreases with age. Happiness also changes as we grow older. We traditionally describe the elderly as annoying or angry; one thing to note in this case is that it is the level of happiness and the feeling of happiness, which change significantly with age. A study by psychologist Heidi Grant Halvorson, published in The Atlantic magazine, found that happiness changes with age. In any case, the quality of life matters significantly in every aspect of life. Especially, as this study focused on the quality of life of empty nesters in Southwest Chinese, the discussion is most appropriate when focused on them. In general, the quality of life of empty nesters is better than that of non-empty nesters in different aspects such as general health, financial soundness, living standards, and so on. However, both the social as well as physiological functions of empty nesters are comparatively lower than the case was with the non-empty nesters [10].

The Chinese culture has a time-honored sophisticated background, particularly in terms of the children's spiritual support for parents in their retirement ages. Nonetheless, some factors influence the children to live separately from their parents, for example, accelerating urbanization, which forces children to live in the urban area and earn their livelihood and parents. This fact that the young people work and live in urban areas leads to parents becoming empty nesters who do not have anybody even to talk to or ask for any help nor other support from society, after their children's departure. These empty-nest elderly experience serious mental health problems, resulting in a lower quality of life. More evidence needs to be provided to find a way to improve the level of quality of life among empty nesters. Our study finds similar results to [7] and highlights that most empty nesters live alone in the Southwest region of China. Besides, this study has found that empty nesters experience low quality of life, given that the average score was 11.42, which is much lower than the score obtained from the normative older population $[10,84]$. This result is consistent with the previous study on the quality of life for elderly people in rural mountainous areas around China [85]. As per Liu and Guo (2007), compared with the non-empty nest group, the empty nest group has lower physical and mental scores, i.e., a lower level of quality of life [10]. In these circumstances, they feel high depression and loneliness in their life. This result is highly similar and consistent with the study of [6]. In line with the literature, Cao et al. [16] and He et al. [10], the bivariate correlation analysis results strongly indicate that both resilience and SS correlated pointedly with quality of life. Specifically, people with greater resilience and experiencing higher levels of support from society can enhance their quality of life in different ways. Concerning empty-nesters in the present study, according to Gerino et al. (2017), those who have greater resilience levels can organize emotional and psychological resources to manage the stressful moments of their lives, and thus, to express and experience a higher level of quality of life. Concerning SS, the prior studies have firmly concluded that supports from family members, friends, or other sources are beneficial to the elderly's mental and physical health $[10,16,17,20]$. Social support is commonly used as a moderator to show the impact of resilience on the quality of life in China's different regions. Therefore, our study has similar findings to those studies, particularly by [42]. It also presents almost similar results. They indicate that supports from society can mitigate the negative impact on the quality of life by protecting them from different types of social and natural adverse effects. Moreover, lack of social support or even lower social support level has a negative impact on the quality of life. The result of [35] shows that lack of social support has a significant impact on prenatal, postnatal, and postpartum depression (PPD). This study also emphasizes that social support has a significant mediating effect, and the quality of life must be improved after an association of social supports in empty nesters' life. This finding also highly supports the result of [21], where they have found that the link between resilience and quality of life shows better after including the social supports. Mainly friends and family supports are highly significant in 
this study; however, the other supports are not significant in empty nesters' quality of life. This study and another study [54] show that except for family and friends' support, other social factors do not significantly influence reducing parenting stress and life satisfaction of the empty nesters.

\section{Implications of This Study}

The better life living standards are an inevitable factor in human life. From birth to old ages, people always prefer to drive towards a better living standard. From the beginning of creation, people are always aware of the issue of quality of life. However, gradually various problems and possibilities appeared with the increase of their ages, especially in the old ages' life after retirement. As young people are statistically becoming one of the largest, influential, and educated generations to date [86], the young society's distance increases abnormally. This unusual growth of older people in the late twentieth century has shown us new challenges for the twenty-first century. The main reason for this challenge is to adapt them and the people around them to the various problems the growing population faces at all levels, such as family, society, and state. In order to raise awareness about ageing and work to improve the multifaceted quality of life of the growing elderly population, we need to know the definition of the elderly, the extent to which the number of the elderly is increasing, expansion of general knowledge, their fundamental human rights, full knowledge of their duties towards them, and positive thinking about them. In these cases, this study will have significant implications not only in Southwest China but also all over China. Therefore, this study suggests that besides the supports from friends and family, the government should extend its hand toward the empty nesters. The nongovernmental organizations should also extend their roles toward the elder societies to reduce their dependency on friends and family. Even the government should extend its hand to the NGOs.

\section{Conclusions}

This study has explored the relations among resilience, support from friends, family, NGOs, government, and quality of life among Chinese empty nesters, particularly in Southwest China. A hierarchical multiple regression analysis has been used in this study to explore the factors. Moreover, using a large sample collected from the empty nesters in Southwest China, the study is focused on exploring the mediating roles of some specific sources of SS, such as family, friends, government, and nongovernment support on the relationship between the main two variables, resilience and the quality of life. Moreover, this study observes which source is more important in the relationship. The results indicate that family members' and friends' resilience and support are significantly related to quality of life. This concept supports Hypotheses 1, 2a, 2b as significantly influencing factors on the quality of life in the empty nesters in Southwest China. We have found that certain other variables also have a significant relationship with the quality of life during this study. For example, loneliness is a variable that significantly influences the living quality among empty nesters. However, nongovernmental support and governmental support do not significantly influence the quality of life. All the subcategories of SS variables such as family support, friends support, governmental, and nongovernmental supports played significant roles in the mediating effects on the link between resilience and the quality of life among the empty nesters in Southwest China.

The present study extends the conclusion by testing the relationship between specific sources of support and quality of life under the conditions in which the demographic data and resilience are controlled. As expected, perceived support from family and friends positively correlated with quality of life. However, the coefficient of support from the government is not significant. There has been a long history in which children have mainly provided the supporting resources; on the other hand, a lousy pension and health-care system in China lead to insufficient support from the government, especially in the countryside. 
However, this study's limitations need to be noted; firstly, data collection from these older people was somewhat tricky. In most cases, the survey team collected data with confusing answers. Secondly, the most significant limitation and one of the most common limitations is the respondents' education level. Thirdly, there is a subjective limitation as NGOs always play vital roles in society; however, it shows an insignificant degree here; even government support also possesses the same limitations for this study. So far, the literature on the subject shows that government support seems insignificant. Therefore, this study suggests more detailed research should be carried out based on these limitations.

Author Contributions: Conceptualization, C.W.; data collection, C.W. and B.Z.; methodology, M.H.; formal analysis, C.W.; writing-original draft, M.H., review, B.Z.; editing, J.O.; revision, M.H.; proofreading M.H. All authors have read and agreed to the published version of the manuscript.

Funding: This paper is supported by EFOP-3.6.3-VEKOP-16-2017-00007__'Young researchers for talent"-supporting careers in research activities in higher education program.

Institutional Review Board Statement: Not applicable.

Informed Consent Statement: Not applicable.

Acknowledgments: We acknowledge the anonymous reviewers of this manuscript.

Conflicts of Interest: The authors declare no conflict of interest.

\section{References}

1. Khan, H.T.A. Population ageing in a globalized world: Risks and dilemmas? J. Eval. Clin. Pract. 2018, 25, 754-760. [CrossRef]

2. Medase, S.K.; Abdul-Basit, S. External knowledge modes and firm-level innovation performance: Empirical evidence from sub-Saharan Africa. J. Innov. Knowl. 2020, 5, 81-95. [CrossRef]

3. ILO. Economic Security for a Better World; International Labour Organization: Geneva, Switzerland, 2004 ; ISBN 9221156117.

4. Peng, L.; Luo, S. Impact of social economic development on personality traits among Chinese college students: A cross-temporal meta-analysis, 2001-2016. Pers. Individ. Dif. 2020. [CrossRef]

5. Abd El-Hamid, H.T.; Caiyong, W.; Hafiz, M.A.; Mustafa, E.K. Effects of land use/land cover and climatic change on the ecosystem of North Ningxia, China. Arab. J. Geosci. 2020, 13. [CrossRef]

6. Su, D.; Wu, X.N.; Zhang, Y.X.; Li, H.P.; Wang, W.L.; Zhang, J.P.; Zhou, L.S. Depression and social support between China' rural and urban empty-nest elderly. Arch. Gerontol. Geriatr. 2012, 55, 564-569. [CrossRef]

7. Cheng, P.; Jin, Y.; Sun, H.; Tang, Z.; Zhang, C.; Chen, Y.; Zhang, Q.; Zhang, Q.; Huang, F. Disparities in prevalence and risk indicators of loneliness between rural empty nest and non-empty nest older adults in Chizhou, China. Geriatr. Gerontol. Int. 2015, 15, 356-364. [CrossRef]

8. Lv, X.L.; Jiang, Y.H.; Sun, Y.H.; Ren, C.Z.; Sun, C.Y.; Sun, L.; Wu, Z.Q.; Zhao, X. Short Form 36-Item Health Survey test result on the empty nest elderly in China: A meta-analysis. Arch. Gerontol. Geriatr. 2013, 56, 291-297. [CrossRef]

9. Wu, Z.Q.; Sun, L.; Sun, Y.H.; Zhang, X.J.; Tao, F.B.; Cui, G.H. Correlation between loneliness and social relationship among empty nest elderly in Anhui rural area, China. Aging Ment. Health 2010, 14, 108-112. [CrossRef]

10. He, W.; Jiang, L.; Ge, X.; Ye, J.; Yang, N.; Li, M.; Wang, M.; Han, X. Quality of life of empty-nest elderly in China: A systematic review and meta-analysis. Psychol. Health Med. 2020, 25, 131-147. [CrossRef] [PubMed]

11. Hyams, A.V.; Hay-McCutcheon, M.; Scogin, F. Hearing and quality of life in older adults. J. Clin. Psychol. 2018, 74, 1874-1883. [CrossRef] [PubMed]

12. Christiansen, L.; Sanmartin Berglund, J.; Lindberg, C.; Anderberg, P.; Skär, L. Health-related quality of life and related factors among a sample of older people with cognitive impairment. Nurs. Open 2019, 6, 849-859. [CrossRef]

13. Howren, M.B.; Cai, X.; Rosenthal, G.; Weg, M.W.V. Associations of Health-Related Quality of Life with Healthcare Utilization Status in Veterans. Appl. Res. Qual. Life 2012, 7, 83-92. [CrossRef]

14. Kolářová, I.; Bédiová, M.; Rašticová, M. Job Opportunities for People Over 50 in the Netherlands. Forum Sci. Oeconomia 2017, 5 , 119-128. [CrossRef]

15. Ewa, M.-W. Age management in an organization. An employee over 50-An opportunity or a limitation for companies. Forum Sci. Oeconomia 2018, 6, 95-106. [CrossRef]

16. Cao, Q.; Qian, Y.; Yang, C. Resilience and quality of life among empty nesters in China: The mediating role of the source of support. J. Gen. Psychol. 2020, 147, 261-276. [CrossRef]

17. Wu, M.; Yang, Y.; Zhang, D.; Zhao, X.; Sun, Y.; Xie, H.; Jia, J.; Su, Y.; Li, Y. Association between social support and health-related quality of life among Chinese rural elders in nursing homes: The mediating role of resilience. Qual. Life Res. 2018, 27, 783-792. [CrossRef] [PubMed]

18. Oleś, M. Resilience and quality of life in chronically ill youth. Health Psychol. Rep. 2015, 3, 220-236. [CrossRef] 
19. Tian, J.; Hong, J.S. Assessment of the relationship between resilience and quality of life in patients with digestive cancer. World J. Gastroenterol. 2014, 20, 18439-18444. [CrossRef]

20. Lee, C.Y.S.; Goldstein, S.E. Loneliness, Stress, and Social Support in Young Adulthood: Does the Source of Support Matter? J. Youth Adolesc. 2016, 45, 568-580. [CrossRef]

21. $\mathrm{Xu}, \mathrm{J} . ; \mathrm{Ou}, \mathrm{L}$. Resilience and quality of life among Wenchuan earthquake survivors: The mediating role of social support. Public Health 2014, 128, 430-437. [CrossRef]

22. Dobriansky, P.J.; Suzman, R.M.; Hodes, R.J. Why Population Aging Matters-A Global Perspective; National Institute on Aging: Bethesda, MD, USA, 2007.

23. Bourassa, K.J.; Memel, M.; Woolverton, C.; Sbarra, D.A. A dyadic approach to health, cognition, and quality of life in aging adults. Psychol. Aging 2015, 30, 449-461. [CrossRef]

24. Roy, K. Fathering From the Long View: Framing Personal and Social Change Through Life Course Theory. J. Fam. Theory Rev. 2014, 6, 319-335. [CrossRef]

25. Albert, A.; Bulcroft, K. Pets, Families, and the Life Course. J. Marriage Fam. 1988, 50, 543-552. [CrossRef]

26. Wang, Z.; Shu, D.; Dong, B.; Luo, L.; Hao, Q. Anxiety disorders and its risk factors among the Sichuan empty-nest older adults: A cross-sectional study. Arch. Gerontol. Geriatr. 2013, 56, 298-302. [CrossRef] [PubMed]

27. Musinszki, Z.; Vallasek, M.; Mélypataki, G.; Csolák, E.H.; Lipták, K. Workaholism and a New Generation-Labour Market Survey among Hungarian and Romanian Youth. Amfiteatru Econ. 2020, 22. [CrossRef]

28. Dabija, D.-C.; Babut, R.; Dinu, V.; Lugojan, M.I. Cross-Generational Analysis of Information Searching based on Social Media in Romania. Transform. Bus. Econ. 2017, 16, 248-270.

29. Chen, Y.; Hicks, A.; While, A.E. Loneliness and social support of older people in China: A systematic literature review. Health Soc. Care Community 2014, 22, 113-123. [CrossRef] [PubMed]

30. Liang, Y.; Wu, W. Exploratory analysis of health-related quality of life among the empty-nest elderly in rural China: An empirical study in three economically developed cities in eastern China. Health Qual. Life Outcomes 2014, 12, 1-16. [CrossRef]

31. Mahmud, A.; Ding, D.; Kiani, A.; Hasan, M.M. Corporate Social Responsibility Programs and Community Perceptions of Societal Progress in Bangladesh: A Multimethod Approach. SAGE Open 2020, 10. [CrossRef]

32. Milgrom, J.; Hirshler, Y.; Reece, J.; Charlene, C.H.; Gemmill Alan, A.W. Social support-a protective factor for depressed perinatal women? Int. J. Environ. Res. Public Health 2019, 16, 1426. [CrossRef]

33. Lawford, J.; Eiser, C. Exploring links between the concepts of quality of life and resilience. Pediatr. Rehabil. 2001, 4, 209-216. [CrossRef]

34. Chou, F.H.C.; Chou, P.; Su, T.T.P.; Ou-Yang, W.C.; Chien, I.C.; Lu, M.K.; Huang, M.W. Quality of life and related risk factors in a Taiwanese Village population 21 months after an earthquake. Aust. N. Z. J. Psychiatry 2004, 38, 358-364. [CrossRef]

35. Xie, R.H.; He, G.; Koszycki, D.; Walker, M.; Wen, S.W. Prenatal Social Support, Postnatal Social Support, and Postpartum Depression. Ann. Epidemiol. 2009, 19, 637-643. [CrossRef] [PubMed]

36. Meyer, D.; Mafini, C. Life Satisfaction by Demography in Low Income Residential Areas: Evidence from South Africa. Stud. Univ. Babes-Bolyai 2016, 61, 31-48.

37. Suchanek, M.; Szmelter-Jarosz, A. Environmental aspects of generation Y's sustainable mobility. Sustainability 2019, 11, 3204. [CrossRef]

38. Jašková, D. Assessment of Social Development in Slovakia in the Context of Human Resources. Cent. Eur. J. Labour Law Pers. Manag. 2019, 2, 21-32. [CrossRef]

39. Cárcaba, A.; González, E.; Ventura, J.; Arrondo, R. How does good governance relate to quality of life? Sustainability 2017, 9, 631. [CrossRef]

40. Puciato, D.; Oleśniewicz, P.; Rozpara, M. Quality of life with respect to physical activity level in the unemployed. Sustainability 2020, 12, 4219. [CrossRef]

41. Johansson, S.; Cheng, S. Universal old-age pension in an aging China: Can China learn from Sweden? Int. Soc. Work 2016, 59, 922-937. [CrossRef]

42. Wang, Z.; Xu, J. Association Between Resilience and Quality of life in Wenchuan Earthquake Shidu parents: The Mediating Role of Social Support. Community Ment. Health J. 2017, 53, 859-863. [CrossRef]

43. Perna, L.; Mielck, A.; Lacruz, M.E.; Emeny, R.T.; Von Eisenhart Rothe, A.; Meisinger, C.; Ladwig, K.H. The association between resilience and diabetic neuropathy by socioeconomic position: Cross-sectional findings from the KORA-Age study. J. Health Psychol. 2015, 20, 1222-1228. [CrossRef]

44. Wiles, J.L.; Wild, K.; Kerse, N.; Allen, R.E.S. Resilience from the point of view of older people: “There's still life beyond a funny knee". Soc. Sci. Med. 2012, 74, 416-424. [CrossRef]

45. Van Kessel, G. The ability of older people to overcome adversity: A review of the resilience concept. Geriatr. Nurs. (Minneap) 2013, 34, 122-127. [CrossRef]

46. Wojewódzka-Wiewiórska, A.; Kłoczko-Gajewska, A.; Sulewski, P. Between the social and economic dimensions of sustainability in rural areas-in search of farmers' quality of life. Sustainability 2020, 12, 148. [CrossRef]

47. Santisi, G.; Lodi, E.; Magnano, P.; Zarbo, R.; Zammitti, A. Relationship between psychological capital and quality of life: The role of courage. Sustainability 2020, 12, 5238. [CrossRef] 
48. Appolloni, A.; Colasanti, N.; Fantauzzi, C.; Fiorani, G.; Frondizi, R. Distance Learning as a Resilience Strategy during Covid-19: An Analysis of the Italian Context. Sustainability 2021, 13, 1388. [CrossRef]

49. Dumitrache, C.G.; Rubio, L.; Rubio-Herrera, R. Perceived health status and life satisfaction in old age, and the moderating role of social support. Aging Ment. Health 2017, 21, 751-757. [CrossRef] [PubMed]

50. Park, J.; Roh, S.; Yeo, Y. Religiosity, social support, and life satisfaction among elderly Korean immigrants. Gerontologist 2012, 52, 641-649. [CrossRef]

51. Ibrahim, N.; Din, N.C.; Ahmad, M.; Ghazali, S.E.; Said, Z.; Shahar, S.; Ghazali, A.R.; Razali, R. Relationships between social support and depression, and quality of life of the elderly in a rural community in Malaysia. Asia-Pac. Psychiatry 2013, 5, 59-66. [CrossRef]

52. Lim, J.W.; Zebrack, B. Different pathways in social support and quality of life between Korean American and Korean breast and gynecological cancer survivors. Qual. Life Res. 2008, 17, 679-689. [CrossRef] [PubMed]

53. Oláh, J.; Hajduová, Z.; Lacko, R.; Andrejovský, P. Quality of Life Regional Differences: Case of Self-Governing Regions of Slovakia. Sustainability 2020, 12, 2924. [CrossRef]

54. Lee, C.Y.S.; Dik, B.J. Associations among stress, gender, sources of social support, and health in emerging adults. Stress Health 2017, 33, 378-388. [CrossRef]

55. Wang, Y.; Huang, Z.; Kong, F. Parenting stress and life satisfaction in mothers of children with cerebral palsy: The mediating effect of social support. J. Health Psychol. 2020, 25, 416-425. [CrossRef]

56. Wu, H.-C.; Chou, P.; Chou, F.H.-C.; Su, C.Y.; Tsai, K.Y.; Ou-Yang, W.C.; Su, T.T.P.; Chao, S.S.; Sun, W.J.; Chen, M.C. Survey of quality of life and related risk factors for a Taiwanese village population 3 years post-earthquake. Aust. N. Z. J. Psychiatry 2006, 40, 355-361. [CrossRef]

57. Greenberg, M.R. The measurement of quality. Med. Gr. Manag. J. 1990, 37, 14. [CrossRef]

58. Osoba, D. The concept of quality of life in oncology. Arch. Oncol. 2004, 12, 166-167. [CrossRef]

59. Ruževičius, J. Quality of Life and of Working Life: Conceptions and Research. Eng. Econ. 2014, 318-334.

60. Ventegodt, S.; Ventegodt, S.; Ventegodt, S.; Ventegodt, S.; Andersen, N.J.; Ventegodt, S.; Andersen, N.J.; Kandel, I.; Kandel, I.; Merrick, J.; et al. Quality of working life research: I. Quality of life, happiness and meaning of life. Int. J. Disabil. Hum. Dev. 2008, 7, 117-126. [CrossRef]

61. Çağlayan-Akay, E.; Sedefoğlu, G. What does bayesian probit regression tell us about Turkish female- and male-headed households poverty? J. Int. Stud. 2017, 10, 46-62. [CrossRef]

62. Campbell-Sills, L.; Stein, M.B. Psychometric analysis and refinement of the Connor-davidson Resilience Scale (CD-RISC): Validation of a 10-item measure of resilience. J. Trauma. Stress 2007, 20, 1019-1028. [CrossRef]

63. Gucciardi, D.F.; Jackson, B.; Coulter, T.J.; Mallett, C.J. The Connor-Davidson Resilience Scale (CD-RISC): Dimensionality and age-related measurement invariance with Australian cricketers. Psychol. Sport Exerc. 2011, 12, 423-433. [CrossRef]

64. Dolores Serrano-Parra, M.; Garrido-Abejar, M.; Notario-Pacheco, B.; Bartolomé-Gutiérrez, R.; Solera-Martínez, M.; MartínezVizcaíno, V. Validez de la escala de resiliencia de Connor-Davidson(10 ítems) en una población de mayores no institucionalizados. Enferm. Clin. 2013, 23, 14-21. [CrossRef]

65. Mishchuk, H.; Samoliuk, N.; Bilan, Y.; Streimikiene, D. Income Inequality and its Consequences within the Framework of Social Justice. Probl. Ekorozwoju 2018, 13, 31-38.

66. Tvaronavičienė, M. Income distribution peculiarities in differently developed selected european countries versus Qatar. J. Int. Stud. 2019, 12, 64-73. [CrossRef]

67. Kwarciński, T.; Ulman, P. Quality of life paradox. Well-being ranking of the selected european countries based on hybrid well-being approach. Econ. Sociol. 2020, 13, 160-180. [CrossRef] [PubMed]

68. Mishchuk, H.; Bilan, S.; Yurchyk, H.; Akimova, L.; Navickas, M. Impact of the shadow economy on social safety: The experience of Ukraine. Econ. Sociol. 2020, 13, 289-303. [CrossRef]

69. Lee, S.C.; Moy, F.M.; Hairi, N.N. Validity and reliability of the Malay version multidimensional scale of perceived social support (MSPSS-M) among teachers. Qual. Life Res. 2017, 26, 221-227. [CrossRef] [PubMed]

70. Balaraju, K. Effectiveness of NGOs and Quality of Life of the Beneficiaries. IRA-Int. J. Manag. Soc. Sci. 2019, 15, 81. [CrossRef]

71. Brown, L.D.; Kalegaonkar, A. Support organizations and the evolution of the NGO sector. Nonprofit Volunt. Sect. Q. 2002, 31, 231-258. [CrossRef]

72. Navajas-Romero, V.; Del Río, L.C.Y.L.; Ceular-Villamandos, N. Analysis of wellbeing in nongovernmental organizations workplace in a developed area context. Int. J. Environ. Res. Public Health 2020, 17, 5818. [CrossRef]

73. Onunkwor, O.F.; Al-Dubai, S.A.R.; George, P.P.; Arokiasamy, J.; Yadav, H.; Barua, A.; Shuaibu, H.O. A cross-sectional study on quality of life among the elderly in non-governmental organizations' elderly homes in Kuala Lumpur. Health Qual. Life Outcomes 2016, 14, 1-10. [CrossRef]

74. Seilerová, M. The Consequences of Psychosocial Risks in the Workplace in Legal Context. Cent. Eur. J. Labour Law Pers. Manag. 2019, 2, 47-60. [CrossRef]

75. Hasan, M.M.; Popp, J.; Oláh, J. Current landscape and influence of big data on finance. J. Big Data 2020, 7, 21. [CrossRef]

76. Hasan, M.M.; Nekmahmud, M.; Yajuan, L.; Patwary, M.A. Green business value chain: A systematic review. Sustain. Prod. Consum. 2019, 20, 326-339. [CrossRef] 
77. Hasan, M.M.; Yajuan, L.; Khan, S. Promoting China's Inclusive Finance Through Digital Financial Services. Glob. Bus. Rev. 2020, 097215091989534. [CrossRef]

78. Nekmahmud, M.; Fekete-Farkas, M. Why not green marketing? Determinates of consumers' intention to green purchase decision in a new developing nation. Sustainability 2020, 12, 7880. [CrossRef]

79. Máté, D.; Rabbi, M.F.; Novotny, A.; Kovács, S. Grand Challenges in Central Europe: The Relationship of Food Security, Climate Change, and Energy Use. Energies 2020, 13, 5422. [CrossRef]

80. Gao, J.; Wang, H.; Shen, H. Machine Learning Based Workload Prediction in Cloud Computing. In Proceedings of the 2020 29th International Conference on Computer Communications and Networks (ICCCN), Honolulu, HI, USA, 3-6 August 2020; pp. 1-9.

81. Gao, J.; Wang, H.; Shen, H. Smartly Handling Renewable Energy Instability in Supporting A Cloud Datacenter. In Proceedings of the 2020 IEEE International Parallel and Distributed Processing Symposium (IPDPS), New Orleans, LA, USA, 18-22 May 2020; pp. 769-778.

82. Gao, J.; Wang, H.; Shen, H. Task Failure Prediction in Cloud Data Centers Using Deep Learning. In Proceedings of the IEEE Transactions on Services Computing, Los Angeles, CA, USA, 9-12 December 2020.

83. Hasan, M.M.; Yajuan, L.; Mahmud, A. Regional Development of China's Inclusive Finance Through Financial Technology. SAGE Open 2020, 10, 215824401990125. [CrossRef]

84. Gerino, E.; Rollè, L.; Sechi, C.; Brustia, P. Loneliness, resilience, mental health, and quality of life in old age: A structural equation model. Front. Psychol. 2017, 8, 1-12. [CrossRef]

85. Liu, L.J.; Guo, Q. Loneliness and health-related quality of life for the empty nest elderly in the rural area of a mountainous county in China. Qual. Life Res. 2007, 16, 1275-1280. [CrossRef]

86. Strydom, C.; Meyer, N.; Synodinos, C. Generation Y university students' intentions to become ecopreneurs: A gender comparison. J. Contemp. Manag. 2020, 17, 22-43. [CrossRef] 